\title{
Effect of dietary incorporation of Vernonia colorata (Willd) leaves on blood lipid profile of albino rats
}

\author{
Ifeoma Irene IJEH $^{1 *}$ and Agatha Chima EGEDIGWE ${ }^{1}$ \\ ${ }^{I}$ Department of Biochemistry, College of Natural Applied Sciences, \\ Michael Okpara University of Agriculture, Umudike, P.M.B 7267, Umuahia, Abia State. \\ *Corresponding Author: ijeh.ifeoma@mouau.edu.ng
}

\begin{abstract}
The effect of 5 and 10\% dietary incorporation of leaves of Vernonia colorata on serum triacyglycerol, cholesterol, high density lipoproteins (HDL), low density lipoproteins (LDL) and very low density lipoproteins (VLDL) was studied in albino rats. Processed and unprocessed leaves of Vernonia colorata (PVC and UPVC) were incorporated into standard Vital feed at 5 and $10 \%$ levels and fed to adult male wistar rats weighing 90$160 \mathrm{~g}$ over a period of 28 days. Feeding of processed and unprocessed Vernonia colorata resulted in significant $(\mathrm{P} \leq 0.05)$ decreases in serum triacylglycerol concentration $(\mathrm{mg} / 100 \mathrm{ml})$ in groups fed with $5 \%$ PVC (133.91 \pm 2.09$), 10 \%$ PVC (110.39 \pm 2.57$), 5 \%$ UPVC (153.74 \pm 1.64$)$ and 10\% UPVC (111.41 \pm 2.30$)$ relative to the control (159.15 \pm 0.32$)$ fed with the basal diet without the vegetable. Serum cholesterol concentration $(\mathrm{mg} / 100 \mathrm{ml})$ also decreased significantly in groups fed 5\% PVC (178.07 \pm 3.46$), 10 \%$ PVC (174.60 \pm 4.21$)$, and $10 \%$ UPVC $(148.77 \pm 1.88)$ relative to the control $(195.31 \pm 4.39)$. Serum HDL concentrations increased significantly in groups fed 5\% PVC (106.02 \pm 2.05$), 10 \%$ PVC (120.15 \pm 2.65$), 5 \%$ UPVC (87.06 \pm 2.47$)$, and $10 \%$ UPVC $(103.33 \pm 2.61)$ relative to the control $(61.79 \pm 0.65)$. Serum LDL concentration decreased significantly in groups fed 5\% PVC (45.27 \pm 2.10$), 10 \%$ PVC (32.38 \pm 3.67$), 5 \%$ UPVC $(73.73 \pm 3.07)$ and $10 \%$ UPVC (23.16 \pm 2.49$)$ relative to control (101.69 \pm 3.66$)$. Serum VLDL Concentrations decreased significantly in groups fed 5\% PVC (26.78 \pm 0.42$), 10 \%$ PVC (22.08 \pm 0.51$), 5 \%$ UPVC (30.75 \pm 0.33$)$ and 10\% UPVC $(22.28 \pm 0.46)$ relative to control $(31.83 \pm 0.06)$. Feeding of Vernonia colorata at $10 \%$ level of dietary incorporation in the unprocessed form resulted in a more marked decrease in serum Triacylglcerols, Cholesterol, LDL and VLDL and increase in HDL. These findings are indicative that dietary incorporation of Vernonia colorata at $10 \%$ levels in both processed and unprocessed forms could have positive modulatory effect on blood lipid profile, by increasing HDL which is beneficial while reducing blood levels of LDL, VLDL and cholesterol which are considered high risk factors for cardiovascular diseases.
\end{abstract}

(C) 2010 International Formulae Group. All rights reserved.

Key words: Vernonia colorata, lipids, cardiovascular diseases, albino rats.

\section{INTRODUCTION}

Cardiovascular diseases (CVDs) are responsible for one third of global deaths and are the leading and increasing contributor to the global disease burden (WHO, 2002). Africa has witnessed increased urbanization and changing lifestyles which have, in turn increased the incidence of CVDs (Kadiri, 
2005). Hypercholesterolemia is a risk factor for CVDs such as atherosclerosis and myocardial infarction which are common causes of mortality and morbidity (Wald and Law, 1995; Krieger, 1998).

Vernonia colorata Willd belongs to the family Compositae (Burkill, 2000) and is relatively non bitter. It can be chewed raw as vegetable or sliced for direct use in soup without prior washing (Ijeh et al., 1996). It is used throughout Africa for the management of a variety of ailments including hypertension. In Nigeria, the Yorubas prescribe the leaf and invoke it and use it against Konu disease (Aubreville, 1959). In Congo, the sap is given for gastrointestinal complaints and for urethral discharge (Bouquet, 1969).Vernonia colorata has been used to cure nausea, abdominal pains, stomachic fever, pile and diarrhea. The aqueous extract has been used by African traditional medicine practitioners as a remedy for the treatment of diabetes (Akah and Okafor, 1992). Ijeh et al. (1996) reported the crude sap of Vernonia colorata as having slight inhibitory activity towards micro organisms. Aqueous extract from Vernonia colorata were also found to be inhibitory for toxoplasma growth (Benoitt et al., 2000). Pharmacological activity studies carried out on the leaves revealed that the leaves possessed high antibacterial activity (Rabe et al., 2002). An extract from Vernonia colorata has been shown to have six anti-inflammatory compounds (Cioff et al., 2004). The hexane extract has hypoglycemic activity (Sy et al., 2005). Processing results in the loss of nutrients and phytochemicals, leading to a reduction in pharmacological activity (Ejoh et al., 2007). There are varied reports on the effects of aqueous, ethanolic and methanolic extracts of Vernonia species on blood lipids.

The present study is aimed at assessing the level of dietary incorporation $(5 \%$ and $10 \%)$ at which the processed and unprocessed Vernonia colorata (PVC and UPVC respectively) can confer beneficial effects on blood lipid profile.

\section{MATERIALS AND METHODS}

Animal and plant materials

Twenty five male albino rats of the wistar strain weighing 90-160 g were purchased from the animal breeding unit of the Faculty of Veterinary Medicine, University of Nigeria, Nsukka, Nigeria. Fresh matured leaves of Vernonia colorata were harvested from farms in the Forestry Research Institute, Ahiaeke Abia State. (Plant cutting bearing leaves were identified by Mr. Ibe .K. Ndukwe a taxonomist at the herbarium unit of Department of Forestry and Environmental Management, Michael Okpara University of Agriculture, Umudike. A voucher specimen of both varieties was also deposited in the herbarium). A portion of the leaves were thoroughly macerated in cold water for 30 mins with several changes of water. They were boiled for ten minutes and air dried to a constant weight and ground in a dry blender and stored in a plastic air-tight container as PVC. A second portion was air dried to a constant weight without processing and ground to fine powder and stored as UPVC.

\section{Experimental procedure}

The animals were separated into five groups of five animals each and housed in stainless steel cages with plastic base under humid tropical conditions. The animals were exposed to $12 \mathrm{~h}$ light/dark cycles and supplied feed and water ad libitum. The protocol conforms to the guidelines of the National Institute of Health (NIH) (NIH publication $85-23,1985)$ for laboratory animal care and use. The animals were allowed to equilibrate on the control feed (Vital grower's feed) for one month before the experimental diets, $5 \%$ and $10 \%$ PVC and UPVC were administered to the experimental groups for 28 days. The control group received growers' feed and water only.

The animals were sacrificed by dazing with a cervical blow and bled by cardiac puncture. 


\section{Serum lipid assay}

Serum lipids and lipoproteins were assayed using commercial kits purchased from RANDOX Laboratories Co (UK). The determination of serum levels of cholesterol was carried out using enzymatic colorimetric endpoint method. It was determined using the cholesterol oxidase method as described by (Richmond, 1973). Serum triacylglycerols were determined using the GPO-PAP method of Trinder (1969) after enzymatic hydrolysis with lipases. The phosphotungstate precipitation method of Richmond (1973) as applied in RANDOX kits were used for the determination of HDL-Cholesterol. The lowdensity lipoprotein (LDL) cholesterol was estimated as the difference between the total cholesterol and the sum of HDL-cholesterol and VLDL cholesterol (Friedewald et al., 1972). The VLDL cholesterol content of serum was determined by calculation from determined triacylglycerols concentration according to method of the Burnstein and Samaille (1960). The serum triacylglycerols concentration was divided by a factor 5 . This factor was based on the understanding that in a fasting human subject with triacylglycerols concentration of $400 \mathrm{mg} / \mathrm{dl}$, the VLDL to total plasma cholesterol ratio is relatively fixed at $1: 5$.

\section{Statistical analysis}

Statistical analysis of data was done using SPSS version 16.0 (SPSS Inc Chicago IL) and $\mathrm{p} \leq 0.05$ considered statistically significant.

\section{RESULTS AND DISCUSSION}

The results show that dietary incorporation of processed Vernonia colorata $(\mathrm{Vc})$ at 5 and $10 \%$ levels in rats resulted in a significant $(\mathrm{P} \leq 0.05) \quad$ decrease in serum triacylglycerols (Figure 1). This decrease was concentration dependent as feeding of $10 \%$ Vernonia colorata at $10 \%$ level in both processed and unprocessed forms resulted in a greater decrease in triacylglycerols concentration than at the 5\% level.
Serum cholesterol (Figure 2), LDLcholesterol (Figure 3) and VLDL-cholesterol (Figure 4) concentrations decreased significantly $(\mathrm{P} \leq 0.05)$ in a concentration dependent pattern in all groups fed the $V c$ incorporated diet. Saponins present in these leaves have been reported to have hypocholesterolemic effects (Price et al., 1987). Saponin bind to cholesterol, and makes it unable to be reabsorbed into the system and therefore excreted from the body (Mayes, 1996). This reduction in serum cholesterol could offer chemoprotective benefits in individuals with hypercholesterolemia reducing the risk of cardiovascular diseases and its attendant morbidity and mortality. LDL -cholesterol poses a risk for CVDs as it transports cholesterol to the arteries, invades the endothelium and becomes oxidized. This oxidized form is easily retained by arterial proteoglycans and thereby trigger plague formation. Increased levels of LDLcholesterol are associated with atherosclerosis, heart attack, stroke and peripheral vascular diseases (Cromwell and Otvos, 2004). Feeding of $V c$ in the unprocessed form resulted in a more marked decrease in the lipid fractions at the $10 \%$ level of incorporation suggesting that processing could reduce the beneficial effect of the vegetable on blood lipid profile.

Figure 5 shows that the serum HDLcholesterol for all groups fed diets incorporated with Vernonia colorata increased significantly $(\mathrm{P} \leq 0.05)$ relative to control. Serum HDL-cholesterol in groups fed with the processed diet at both levels was significantly higher than their counterparts fed with unprocessed diets. This suggests that feeding experimental animals with Vernonia colorata may probably play an antiatherogenic role. HDL-cholesterol promotes the reverse cholesterol transport pathway by inducing the efflux of excess accumulated cellular cholesterol and prevents the generation of an oxidized modified 


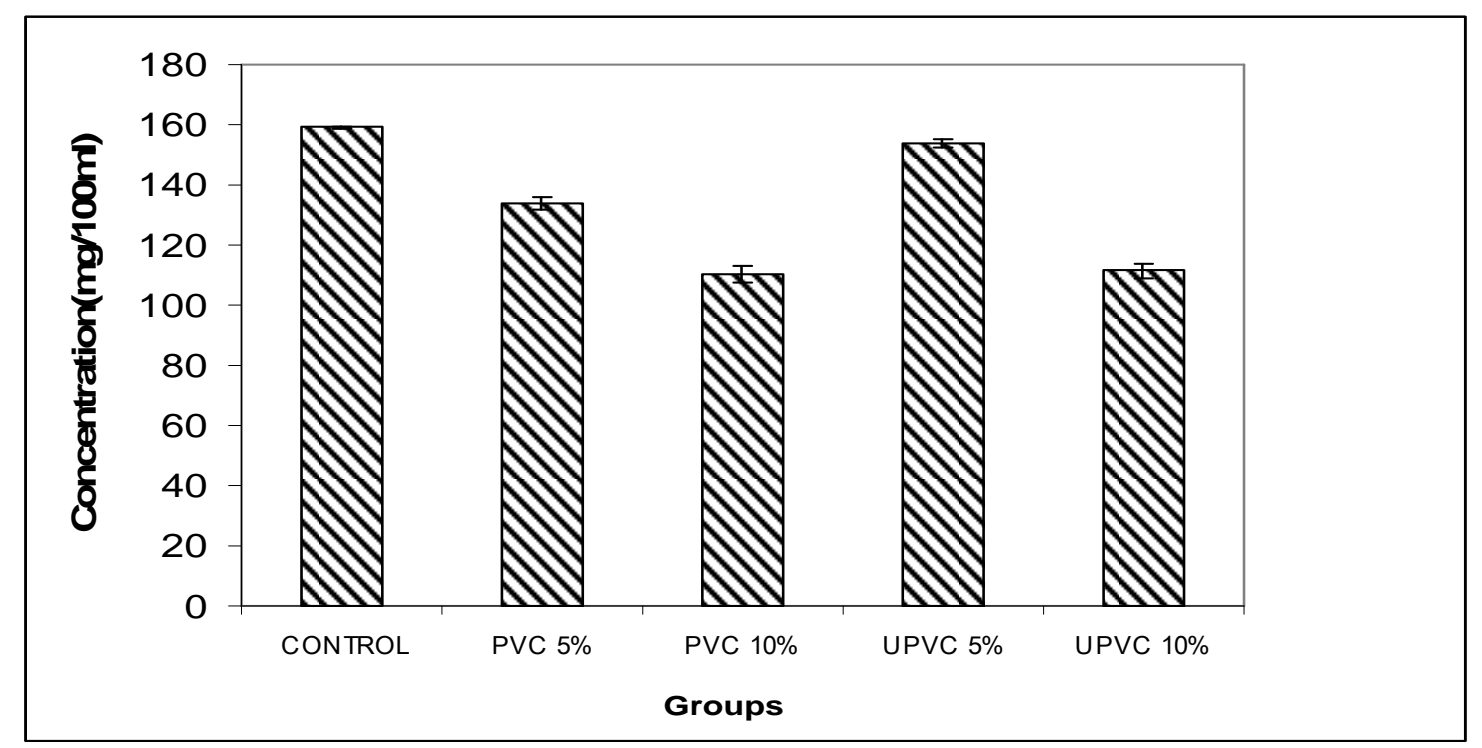

Figure 1: Serum triacylglycerol in rats fed with processed and unprocessed Vernonia colorata incorporated diets.

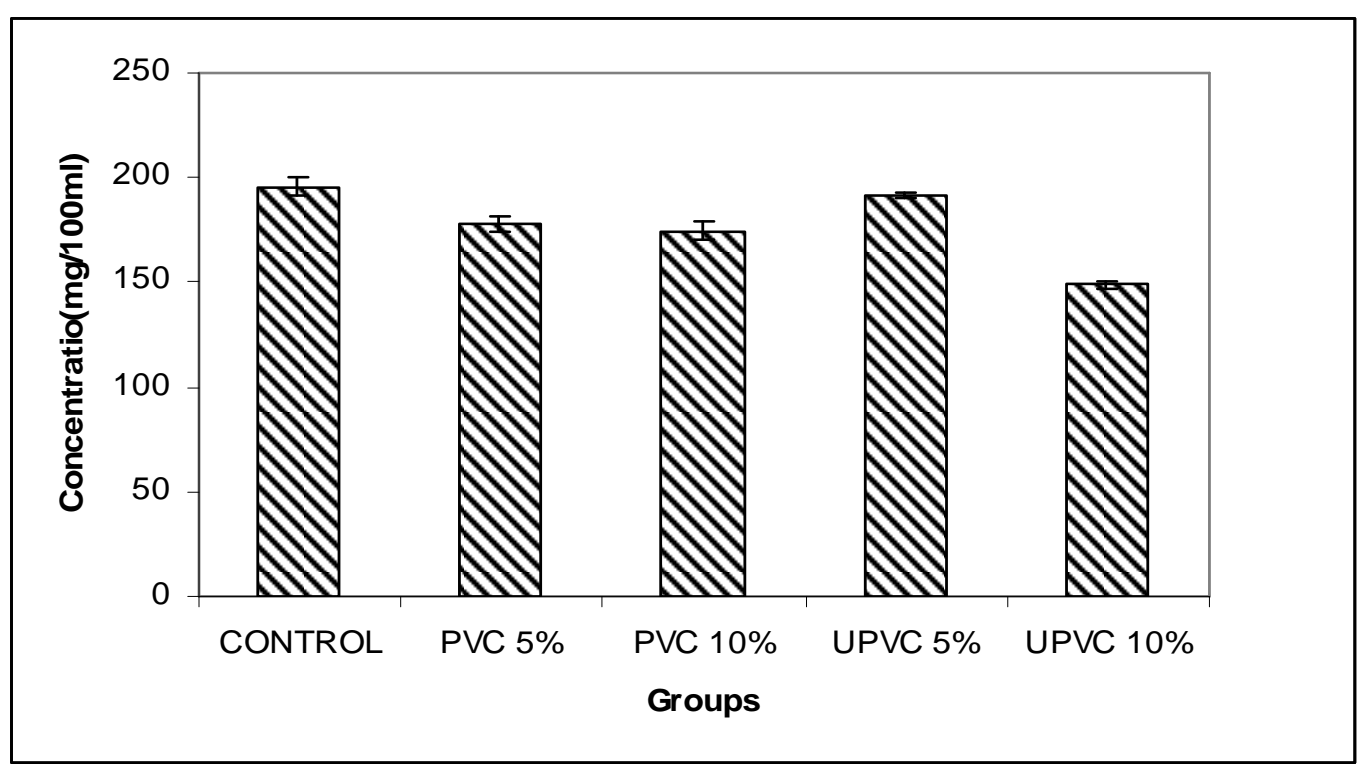

Figure 2: Cholesterol concentration in rats fed with processed and unprocessed Vernonia colorata incorporated diets. 


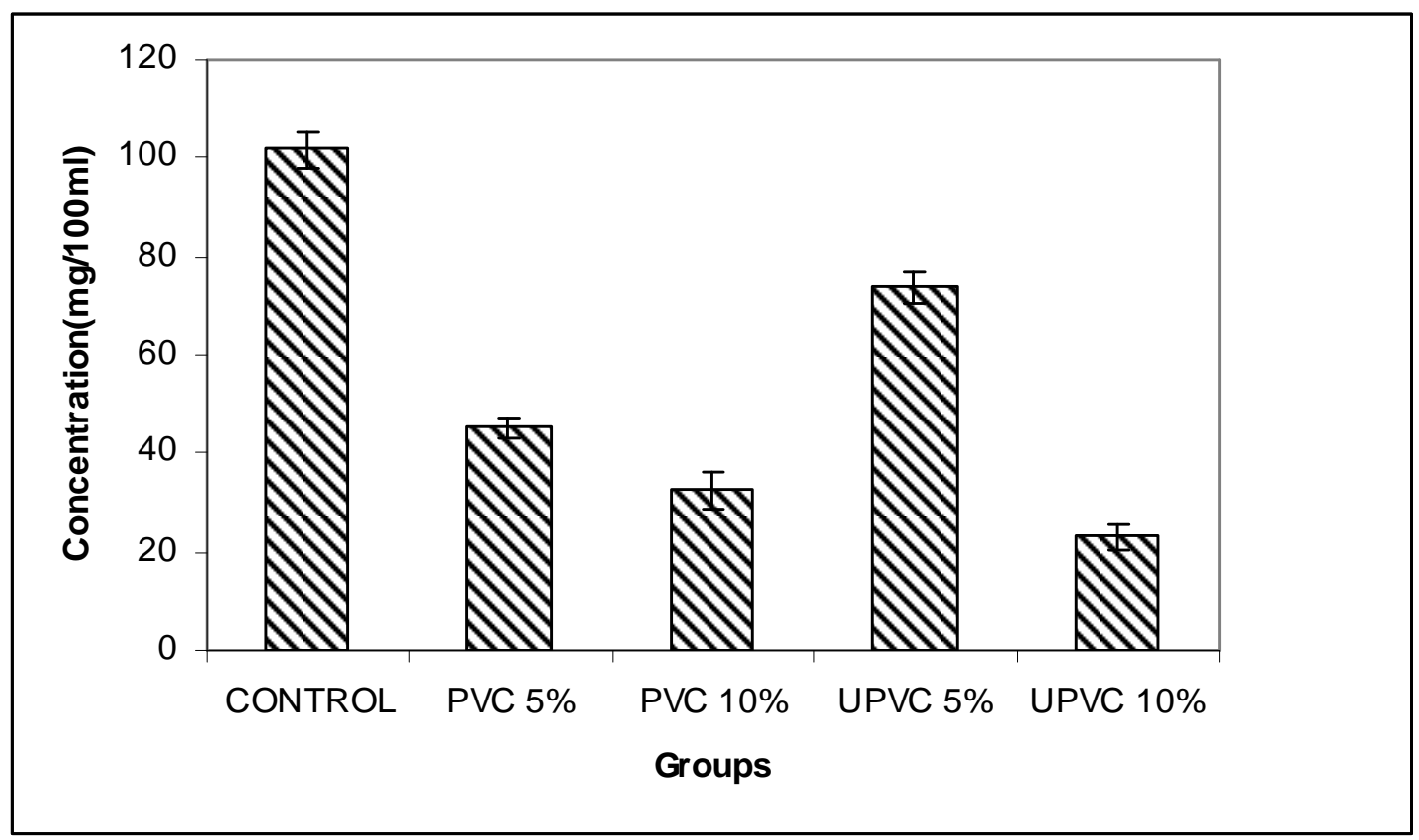

Figure 3: LDL-cholesterol concentrations in rats fed with processed and unprocessed Vernonia colorata incorporated diets.

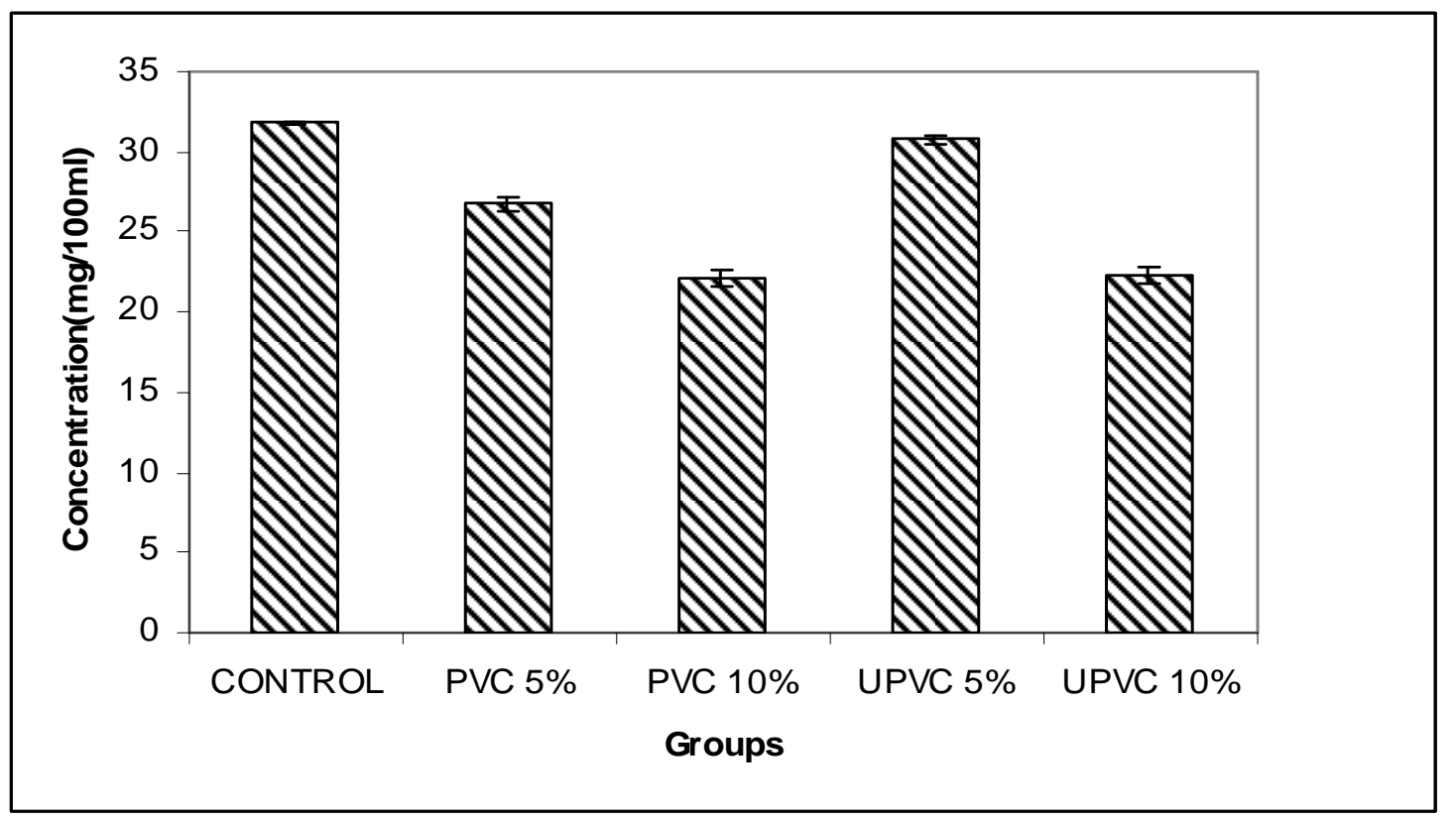

Figure 4: VLDL-cholesterol concentrations in rats fed with processed and unprocessed Vernonia colorata incorporated diets. 


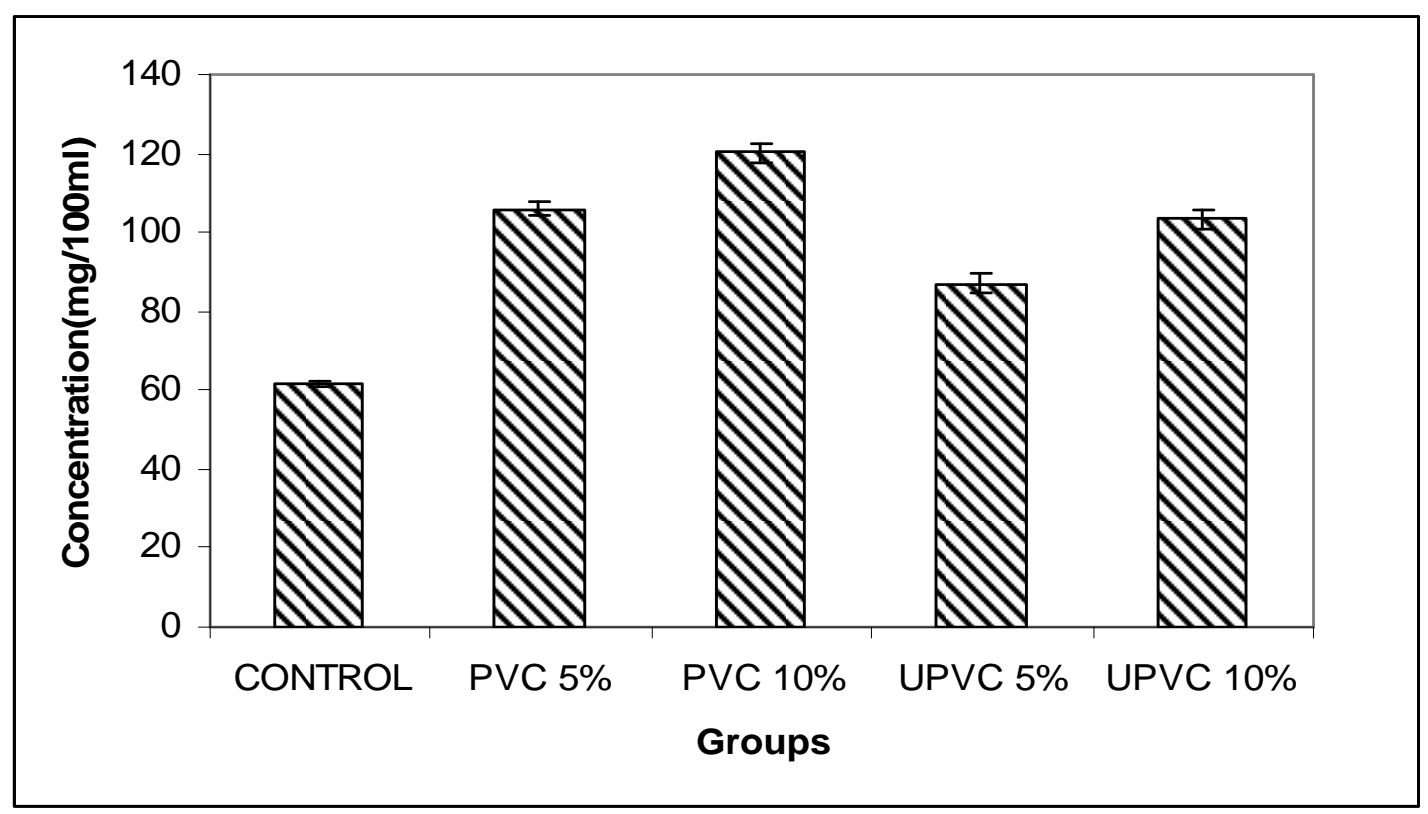

Figure 5: HDL-cholesterol concentrations in rats fed with processed and unprocessed Vernonia colorata incorporated diets.

LDL (Yokozawa et al., 2006). It could also promote the pathway by removing cholesterol from the atheroma within the arteries and transport it back to the liver for excretion or re-utilization. It is hypothesized that high level of HDL-cholesterol protect against Cardiovascular Diseases (Kwiterovich, 2000).

These findings are indicative that Vernonia colorata could have a positive modulatory effect on blood lipid profile by reducing blood levels of lipids with atherogenic potentials (LDL and VLDL) while increasing HDL that has a cardio protective effect. This finding could justify the ethnomedicinal use of Vernonia colorata in the management of diabetes mellitus which is associated with abnormalities in lipid metabolism ( Sy et al., 2005).

This leafy vegetable could be beneficial for individuals predisposed to cardiovascular diseases. Vernonia colorata is less bitter than the more popularly used Vernonia amygdalina. It involves less tedious processing and is often used in the unprocessed form which has been shown in the present study to have higher hypolipidaemic potentials. Its consumption should therefore be encouraged in individuals predisposed to CVDs.

\section{REFERENCES}

Akah PA, Okafor CL. 1992. Blood sugar lowering effect of Vernonia amygdalina (Del) in an experimental rabbit model. Phytotherapy Research., 6: 171-173.

Aubreville A. 1959. Flore Forestiere de la Cote d'Ivore Centre Tech.Forest. Trop. Nogent Pp 960 Bouquet A. 1969. Feticheurs et medicines traditionnelles du Congo (Brazzaville). Mem. O.R.S.T.O.M., 36 p 282.

Benoit VF, Santiallana-Hayat M, KoneBamba D, Mallie M, Deroun F. 2000. Anti-toxoplasma activity of vegetal extracts used in West African traditional medicine. J. Ethnopharmacol., 7: 1.

Bouquet A. 1969. Feticheurs et Medicines Traditionnelles du Congo - Brazzaville. Mem. O.R.S.T.O.M, 36, p. 282. 
Burkill HM. 2000. The Useful Plants of West Tropical Africa (2 $2^{\text {nd }}$ edn, Vol. 5). Royal Botanic Gardens: Kew, United Kingdom.

Burnstein M, Samaille J. 1960. A Rapid Determination of Cholesterol Bound to 7 and B Hyperborean. Clin. Chem. Acta., 5: 604-635.

Cioff G, Sanogo R, Diallo D, Romussi G, De Tommasi N. 2004. New compounds from an extract of Vernonia colorata leaves with inflammatory activity. J. Nat Prod., 67(3): 389-394.

Cromwell WC, Otvos JD. 2004. Low Density lipoprotein particles number and risk for cardiovascular disease. Curr Atheroscler Rep., 6:381-387.

Ejoh RA, Konga DV, Innocent G, Moses MC. 2007. Effect of the method of processing and preservation on some quality parameters of three non-conventional leafy vegetables. Pakistan Journal of Nutrition, 6(2): 128-133.

Friedewald WT, Levy RI, Frederickson DS. 1972. Estimation of the concentration of LDL cholesterol in plasma, without use of the preparative ultra- centrifuge. Clin Chem., 18: 499-502.

Glew RH, Kassam HA, Bhanj RA, Okorodudu A, Vanderjagt DJ. 2002. Serum lipid profiles and risk of cardiovascular disease in three different male populations in northern Nigeria. $J$. Health. Popul. Nutr., 20: 166-174.

Ijeh II, Nwugo VO, Obidoa O. 1996. Comparative studies on the nutritive Phyto-chemical and antimicrobial properties of two varieties of Vernomia amygdalina. Plant Prod. Res. Comm., 1: 71-75.

Kadiri S. 2005. Tackling cardiovascular disease in Africa. BMJ, 331: 711-712.

Krieger M. 1998. The "best" of cholesterols, the "worst" of cholesterols: a tale of two receptors. Proc Natl Acad Sci USA, 95: 4077-4080.
Kwiterovich PO. 2000. The metabolic pathway of high density lipoprotein and triacylglycerol. Cardiol., 86: 120-128.

Mayes PA. 1996. Cholesterol Synthesis, Transport and Excretion In Harper's Biochemistry $\left(24^{\text {th }}\right.$ edn), Murrary RK et al.; Prince-Hall Internal Inc: California. U. A; 271-280.

Price KR, Johnson LI, Feriwick H. 1987. The chemical and biological significance of saponins in foods and feeding stuffs. CRC Critical Review. Food Science and Nutrition 26: 127-135.

Rabe T, Mullholland D, Van Staden J. 2002. Isolation and identification of antibacterial compounds from Vernonia colorata leaves. J. Ethnopharmacol. 80(1): 91-94.

Richmond W. 1973. Cholesterol enzymatic colorimetric test chop-PAP method of estimation of total cholesterol in serum. Clin. Chem., 191: 1350-1356.

Sy GY, Cisse A, Nongonierma RB, Sarr M, Mbodj NA, Faye B. 2005. Hypoglycaemic and antidiabetic activity of acetonic extract of Vernonia colorata leaves in normoglycaemic and alloxan induced diabetic rats. $J$. Ethnopharmacol., 98(1-2): 171-175.

Trinder P. 1969. Triglycerides estimation by GPO-PAP method. Ann. Clin. Chem., 6: $24-27$.

Wald NJ, Law MR. 1995. Serum cholesterol and ischaemic heart disease. Atherosclerosis, 118: 1-5.

WHO. 2002. Traditional Medicine Strategy 2002-2005. WHO: Geneva.

Yokozawa T, Cho EJ, Sasaki S, Satoh A, Okamoto T, Sei Y. 2006. The protective role of Chinese prescription Kangenkaryu extract on diet-induced hypercholesterolemia in rats. Biol. Pharm. Bull., 29: 760-765. 